\title{
Management of antiphospholipid syndrome
}

\author{
Anisur Rahman ${ }^{1}$ (D)
}

Received: 4 May 2020 / Revised: 17 May 2020 / Accepted: 18 May 2020 / Published online: 26 May 2020

(C) International League of Associations for Rheumatology (ILAR) 2020

\begin{abstract}
Antiphospholipid syndrome (APS) is an autoimmune disease characterised by vascular thrombosis and/or pregnancy morbidity in the presence of persistently positive serum tests for antiphospholipid antibodies. Management of APS centres on preventing these clinical events and in preventing chronic damage caused by these events. In patients with thrombotic APS, long-term anticoagulation is recommended in the majority of cases. Although there were hopes that direct-acting oral anticoagulants could replace warfarin for prevention of thrombosis in patients with APS, this now seems less likely due to recent trial results. There is no evidence for use of anticoagulation in people who are aPLpositive but have never had a thrombosis but low-dose aspirin may be beneficial in those who have a higher-risk aPL profile. Management of obstetric APS is with daily subcutaneous heparin and low-dose aspirin. This gives a live birth rate of $70 \%$ or more. Catastrophic APS is rare, occurring in 1\% of patients with APS. It is characterised by thrombosis in multiple organs simultaneously, with a high mortality rate. The management is with corticosteroids, anticoagulation, and immunoglobulins or plasma exchange.
\end{abstract}

Keywords Anticoagulation $\cdot$ Antiphospholipid syndrome $\cdot$ Thrombosis

Antiphospholipid syndrome (APS) is an autoimmune disease characterised by the presence of antiphospholipid antibodies $(\mathrm{aPL})$ in patients who suffer either vascular thrombosis, pregnancy morbidity, or both [1]. The aPL is measured in clinical practice by three different assays: the anticardiolipin enzymelinked immunosorbent assay (ELISA), the lupus anticoagulant test, and the anti-beta-2-glycoprotein I ELISA. Patients who test persistently positive in all three of these tests are termed triple-positive and have a higher risk of thrombosis than those who are single or double-positive [2]. APS was first described in patients with systemic lupus erythematosus (SLE) and often co-exists with that condition [3]. However, it can also exist separate from any other medical condition - this is termed primary antiphospholipid syndrome (PAPS).

Catastrophic antiphospholipid syndrome (CAPS) is a very rare form of APS ( $1 \%$ of cases) in which there are thromboses in multiple organs simultaneously, with a high mortality [4]. In this issue of Clinical Rheumatology, Mesa et al. discuss

Anisur Rahman

anisur.rahman@ucl.ac.uk

1 Centre for Rheumatology Research, Division of Medicine, University College London, London, UK their experience of treating 7 patients with CAPS and raise the issue of whether lifelong anticoagulation is required in these patients.

According to an epidemiological study in 2019, the incidence of APS is 2 per 100,000 per year and prevalence about 50 per 100,000 [5]. However, there is a larger group of patients who are positive in one or more of the aPL tests but have never suffered vascular thrombosis or pregnancy morbidity. For example, $20-30 \%$ of patients with SLE may test positive for aPL, but not all of these patients will develop clinical APS.

It is important to be aware that the management of APS in most patients is not a question of relieving current symptoms but of reducing the future risk that the patient will develop thrombosis or pregnancy morbidity. Thus, a patient may be in the position of taking long-term anticoagulation - with all the attendant side effects - in order to prevent something that may or may not happen. This balance between risk prevention and potential side effects of treatment creates challenges in management of patients with APS and people who are aPL-positive. These challenges have been addressed in European League Against Rheumatism (EULAR) guidelines in 2019 [6] and can be considered under the following headings. 


\section{Primary prophylaxis of thrombosis in people who are aPL-positive}

There is no evidence supporting the use of anticoagulation in aPL-positive subjects with no history of thrombosis or pregnancy morbidity. In general, the risks of treatment would outweigh the benefits. It is important, however, not to forget to give simple lifestyle advice to these individuals - not smoking, avoiding the combined oral contraceptive pill, walking around on long flights. It is also advisable to involve a haematologist in the management-it may be that the patient also has a non-aPL-related risk factor for thrombosis such as Factor V Leiden such that the total calculation of risk favours anticoagulation.

Regarding use of aspirin for primary prophylaxis, the evidence is varied. A single randomised controlled trial on 98 patients found that aspirin did not have a beneficial effect [7]. A meta-analysis of 10 observational studies and one interventional study suggested that higher-quality studies did not support use of aspirin either [8], but a subsequent more detailed analysis of five of those studies by the same authors included individual patient data. This allowed adjustment for effects of non-aPL thrombosis risk factors, and the analysis suggested that use of low-dose aspirin halved risk of thrombosis in aPL-positive patients (hazard ratio $0.43,95 \%$ confidence intervals 0.25 to 0.75 ) [9].

The EULAR guidelines therefore suggest use of low-dose aspirin in those with high-risk aPL profiles (e.g. triple-positive) [6].

\section{Prevention of recurrent thrombosis in patients with confirmed APS}

The evidence for this group clearly supports use of long-term anticoagulation. Two meta-analyses $[10,11]$ concluded that patients who fulfil the classification criteria for APS should be anti-coagulated long-term to prevent further thrombosis and advised higher-intensity anticoagulation in those with arterial thrombosis (typically INR of 3-4) compared to those with venous thrombosis only (typically INR of $2-3$ ). The EULAR guidelines, however, distinguish provoked and unprovoked thrombosis and suggest that where there has been a single venous thrombosis that was clearly provoked by a stimulus, long-term anticoagulation may only be necessary in high-risk groups [6].

In recent years, there has been great interest in the idea of replacing warfarin with the new direct oral anticoagulants (DOACs) such as rivaroxaban and apixaban in patients with APS. The DOACs target single-clotting factors (such as Factor $\mathrm{X}$ for rivaroxaban) and have potential advantages such as not needing regular blood tests and having fewer interactions with other drugs. Two randomised controlled studies comparing rivaroxaban with warfarin in patients with APS have been reported. The RAPS study in the UK randomised 110 patients and found that rivaroxaban was non-inferior to warfarin in a laboratory outcome measure [12]. There were no thromboses in either treatment group. However, the TRAPS study in Italy (which unlike RAPS included only high-risk triple-positive patients) was halted prematurely because of an excess of adverse events in the rivaroxaban arm. Of the patients on rivaroxaban, 11/59 suffered ischaemic stroke, myocardial infarction or major haemorrhage, compared to $2 /$ 61 in the warfarin arm [13]. Although there is still discussion about whether the DOACs could have a role to play in lowerrisk patients with APS, current advice is not to start these agents in patients with APS. In patients already taking DOACs, an individual discussion with each patient about the pros and cons of continuing the DOAC or changing back to warfarin is important.

Corticosteroids are not beneficial in APS (with the exception of CAPS - see below). Hydroxychloroquine is widely used, especially in patients who also have SLE. It may help symptoms such as arthralgia, but there is no proven effect on reducing thrombotic risk. However, hydroxychloroquine has a number of biological effects that might potentially protect against thrombosis. For this reason, a large multi-national randomized study (HIBISCUS) has been proposed to define the potential beneficial effects of this drug in both obstetric and thrombotic APS. Belizna et al. have described the plan for the study and also reviewed previous clinical data on use of hydroxychloroquine in APS [14].

\section{Management of pregnancy in APS}

For patients with a clear history of obstetric APS (generally, three successive first trimester miscarriages or one late pregnancy loss in the presence of persistent serum aPL), the standard management is with low-dose aspirin plus daily subcutaneous heparin throughout the pregnancy. This regime is consistently reported to give a $70 \%$ live birth rate [15] though there may be other pregnancy complications such as intra-uterine growth retardation or post-partum haemorrhage. Warfarin is contraindicated in pregnancy due to teratogenicity. Since the post-partum period is one of at high risk for thrombosis, the EULAR guidelines recommend continuing heparin for 6 weeks after birth [6]. For patients with only obstetric manifestations of APS, who have never had thrombosis, long-term anticoagulation between pregnancies is not necessary.

In patients who have never been pregnant and are now planning a first pregnancy in the knowledge that they are aPL-positive, it is important to take individual circumstances into account. For example, in a patient where there are good reasons (such as older age) to believe that it may be difficult to 
become pregnant again, there may be an impetus to treat with aspirin (or even aspirin and heparin) in order to give this pregnancy the best chance of success. This, however, would not be evidence-based and any such decision would be made in close consultation with the obstetrician and the patient.

\section{Management of catastrophic antiphospholipid syndrome}

In this rare but life-threatening form of APS, there is often multi-organ failure [4]. It is a medical emergency and, as described by Mesa et al. in this issue, urgent treatment with a combination of anticoagulation, corticosteroids and immunoglobulins or plasma exchange is essential [4]. Where there is necrosis of digits or whole limbs, the vascular surgeons may be involved.

Mesa et al. review literature on whether all patients with APS require lifelong anticoagulation and report favourable outcomes from withdrawing anticoagulation in their 7 patients. Five did not suffer any further thrombosis over a mean follow-up period of 5.5 years. Given that the overall principle of anticoagulation in APS is to reduce risk of recurrent events, and that patients with CAPS have had the most severe previous events of any patients with APS, one might consider that the balance of risk in those patients might particularly favour need for treatment. On the other hand, Mesa et al. rightly point out possible side effects of anticoagulation.

Given the rarity of CAPS, it seems unlikely that it would be easy to carry out a randomised controlled trial to address the question of whether anticoagulation can safely be withdrawn in these patients.

\section{Conclusion}

The primary aim of treatment in patients with APS is to reduce risk of thrombosis or pregnancy morbidity. To prevent recurrent thrombosis, long-term anticoagulation is advised though this may not be necessary for all patients in whom there was a single provoked venous thrombosis. Currently, starting DOACs is not advised for patients with APS. Combination therapy with heparin and aspirin gives a live birth rate of $70 \%$ in patients with obstetric APS. CAPS is a medical emergency requiring urgent treatment with anticoagulation, corticosteroids and intravenous immunoglobulins or plasma exchange.

\section{Compliance with ethical standards}

Disclosures None.

\section{References}

1. Miyakis S, Lockshin MD, Atsumi T, Branch DW, Brey RL, Cervera R, Derksen RH, PG DEG, Koike T, Meroni PL, Reber G, Shoenfeld Y, Tincani A, Vlachoyiannopoulos PG, Krilis SA (2006) International consensus statement on an update of the classification criteria for definite antiphospholipid syndrome (APS). J Thromb Haemost 4(2):295-306

2. Pengo V, Ruffatti A, Legnani C, Greseli P, Barcellona D, Erba N, Testa S, Marongiu F, Bison E, Denas G, Banzato A, Padayyatil Jose S, Iliceto S (2010) Clinical course of high-risk patients diagnosed with antiphospholipid syndrome. J Thromb Haemost 8:237242

3. Hughes GR (1983) Thrombosis, abortion, cerebral disease, and the lupus anticoagulant. Br Med J (Clin Res Ed) 287(6399):1088-1089

4. Cervera R, Rodriguez-Pinto I, Espinosa G (2018) The diagnosis and clinical management of the catastrophic antiphospholipid syndrome: a comprehensive review. J Autoimmun 92:1-11. https://doi. org/10.1016/j.jaut.2018.05.007

5. Duarte-Garcia A, Pham MM, Crowson CS, Amin S, Moder KG, Pruthi RK, Warrington KJ, Matteson EL (2019) The epidemiology of antiphospholipid syndrome: a population-based study. Arthritis Rheumatol 71(9):1545-1552. https://doi.org/10.1002/art.40901

6. Tektonidou MG, Andreoli L, Limper M, Amoura Z, Cervera R, Costedoat-Chalumeau N, Cuadrado MJ, Dorner T, FerrerOliveras R, Hambly K, Khamashta MA, King J, Marchiori F, Meroni PL, Mosca M, Pengo V, Raio L, Ruiz-Irastorza G, Shoenfeld Y, Stojanovich L, Svenungsson E, Wahl D, Tincani A, Ward MM (2019) EULAR recommendations for the management of antiphospholipid syndrome in adults. Ann Rheum Dis 78(10): 1296-1304. https://doi.org/10.1136/annrheumdis-2019-215213

7. Erkan D, Harrison MJ, Levy R, Peterson M, Petri M, Sammaritano L, Unalp-Arida A, Vilela V, Yazici Y, Lockshin MD (2007) Aspirin for primary thrombosis prevention in the antiphospholipid syndrome: a randomized, double-blind, placebo-controlled trial in asymptomatic antiphospholipid antibody-positive individuals. Arthritis Rheum 56(7):2382-2391. https://doi.org/10.1002/art. 22663

8. Arnaud L, Mathian A, Ruffatti A, Erkan D, Tektonidou M, Cervera R, Forastiero R, Pengo V, Lambert M, Martinez-Zamora MA, Balasch J, Zuily S, Wahl D, Amoura Z (2014) Efficacy of aspirin for the primary prevention of thrombosis in patients with antiphospholipid antibodies: an international and collaborative meta-analysis. Autoimmun Rev 13(3):281-291. https://doi.org/10. 1016/j.autrev.2013.10.014

9. Arnaud L, Mathian A, Devilliers H, Ruffatti A, Tektonidou M, Forastiero R, Pengo V, Lambert M, Lefevre G, Martinez-Zamora MA, Balasch J, Wahl D, Amoura Z (2015) Patient-level analysis of five international cohorts further confirms the efficacy of aspirin for the primary prevention of thrombosis in patients with antiphospholipid antibodies. Autoimmun Rev 14(3):192-200. https://doi.org/10.1016/j.autrev.2014.10.019

10. Lim W, Crowther MA, Eikelboom JW (2006) Management of antiphospholipid antibody syndrome: a systematic review. Jama 295(9):1050-1057

11. Ruiz-Irastorza G, Hunt BJ, Khamashta MA (2007) A systematic review of secondary thromboprophylaxis in patients with antiphospholipid antibodies. Arthritis Rheum 57(8):1487-1495. https://doi.org/10.1002/art.23109

12. Cohen H, Hunt BJ, Efthymiou M, Arachchillage DR, Mackie IJ, Clawson S, Sylvestre Y, Machin SJ, Bertolaccini ML, RuizCastellano M, Muirhead N, Dore CJ, Khamashta M, Isenberg DA, investigators Rt (2016) Rivaroxaban versus warfarin to treat patients with thrombotic antiphospholipid syndrome, with or without systemic lupus erythematosus (RAPS): a randomised, 
controlled, open-label, phase $2 / 3$, non-inferiority trial. Lancet Haematol 3(9):e426-e436. https://doi.org/10.1016/S23523026(16)30079-5

13. Pengo V, Denas G, Zoppellaro G, Jose SP, Hoxha A, Ruffatti A, Andreoli L, Tincani A, Cenci C, Prisco D, Fierro T, Gresele P, Cafolla A, De Micheli V, Ghirarduzzi A, Tosetto A, Falanga A, Martinelli I, Testa S, Barcellona D, Gerosa M, Banzato A (2018) Rivaroxaban vs warfarin in high-risk patients with antiphospholipid syndrome. Blood 132(13):1365-1371. https://doi.org/10.1182/ blood-2018-04-848333

14. Belizna C, Pregnolato F, Abad S, Alijotas-Reig J, Amital H, Amoura Z, Andreoli L, Andres E, Aouba A, Apras Bilgen S, Arnaud L, Bienvenu B, Bitsadze V, Blanco P, Blank M, Borghi MO, Caligaro A, Candrea E, Canti V, Chiche L, Chretien JM, Cohen Tervaert JW, Damian L, Delross T, Dernis E, Devreese K, Djokovic A, Esteve-Valverde E, Favaro M, Fassot C, FerrerOliveras R, Godon A, Hamidou M, Hasan M, Henrion D, Imbert B, Jeandel PY, Jeannin P, Jego P, Jourde-Chiche N, Khizroeva J, Lambotte O, Landron C, Latino JO, Lazaro E, de Leeuw K, Le Gallou T, Kilic L, Limper M, Loufrani L, Lubin R, Magy-
Bertrand N, Mahe G, Makatsariya A, Martin T, Muchardt C, Nagy G, Omarjee L, Van Paasen P, Pernod G, Perrinet F, Pires Rosa G, Pistorius MA, Ruffatti A, Said F, Saulnier P, Sene D, Sentilhes L, Shovman O, Sibilia J, Sinescu C, Stanisavljevic N, Stojanovich L, Tam LS, Tincani A, Tollis F, Udry S, Ungeheuer MN, Versini M, Cervera R, Meroni PL (2018) HIBISCUS: Hydroxychloroquine for the secondary prevention of thrombotic and obstetrical events in primary antiphospholipid syndrome. Autoimmun Rev 17(12):1153-1168. https://doi.org/10.1016/j. autrev.2018.05.012

15. de Jesus GR, Agmon-Levin N, Andrade CA, Andreoli L, Chighizola CB, Porter TF, Salmon J, Silver RM, Tincani A, Branch DW (2014) 14th international congress on antiphospholipid antibodies task force report on obstetric antiphospholipid syndrome. Autoimmun Rev 13(8):795-813. https://doi.org/10.1016/j.autrev.2014.02.003

Publisher's note Springer Nature remains neutral with regard to jurisdictional claims in published maps and institutional affiliations. 